\title{
The use of recombinant human thyrotropin (Thyrogen) in the diagnosis and treatment of thyroid cancer
}

\author{
Leonidas H. Duntas ${ }^{1}$, Nikolaos Tsakalakos ${ }^{2}$, Brigitte Grab-Duntas ${ }^{3}$, \\ Maria Kalarritou ${ }^{1}$, Elli Papadodima ${ }^{4}$ \\ ${ }^{1}$ Endocrine Unit, Evgenidion Hospital, University of Athens Medical School, ${ }^{2}$ Iaso General Hospital, \\ ${ }^{3}$ Institute of Isotopic Studies, ${ }^{4}$ Henry Dunant Hospital, Athens, Greece
}

\begin{abstract}
The introduction of human recombinant thyrotropin (rhTSH/Thyrogen) into the diagnosis of thyroid cancer has substantially ameliorated the patient's quality of life through the avoidance of debilitating hypothyroidism. With the aim of updating the use of Thyrogen, we report 7 cases which were treated with Thyrogen for diagnostic or therapeutic purposes. All 7 patients were thyroidectomised and radioiodine ablated and all had detectable $[>1 \mathrm{ng} / \mathrm{ml}]$ basal serum thyroglobulin (b$\mathrm{Tg}$ ) levels. Thyrogen stimulation resulted in a rise of $\mathrm{Tg}(\mathrm{s}-\mathrm{Tg})$ in all patients. Five patients had negative whole body scanning (WBS) and no clinical or radiological signs of disease. Two patients with a b-Tg value of $5 \mathrm{ng} / \mathrm{ml}$ and $11 \mathrm{ng} / \mathrm{ml}$, respectively showed a s-Tg of $17 \mathrm{ng} / \mathrm{ml}$ and $84 \mathrm{ng} / \mathrm{ml}$, respectively, whereas WBS was negative. Both of these patients received $100 \mathrm{mCi}(3700 \mathrm{MBq}){ }^{131} \mathrm{I}$. Two patients had a positive Tg and positive WBS with skull, lung and hepatic metastases and received $150{ }^{131} I$ after preparation with Thyrogen. Six months later one of these patients was free of disease and the other will be evaluated during the coming months. In conclusion, Thyrogen emerges as a reliable and safe agent for the diagnosis of thyroid cancer. Furthermore, it appears that Thyrogen could be used in the treatment of metastases as an alternative to thyroid hormone withdrawal.
\end{abstract}

Key Words: human recombinant TSH, thyroglobulin, thyroid cancer, radiotherapy

\section{INTRODUCTION}

Over the last two decades a steady increase in the incidence of thyroid cancer has been observed ${ }^{1}$. This may be due to a variety of environmental factors com-

\footnotetext{
Address correspondence and requests for reprints to: Leonidas H. Duntas, M.D. Endocrine Unit, Evgenidion Hospital, University of Athens, 20 Papadiamantopoulou Str., 11528 Athens, Greece, Tel.: +30 2106748878 ,

Fax:+302106756718, e-mail: ledunt@otenet.gr

Received 28-05-03, Revised 15-06-03, Accepted 30-06-03
}

bined with an increased awareness and better screening $^{2,3}$. Successful management of thyroid cancer is based on total thyroidectomy followed by radioiodine ablation and thyroxine therapy in TSH-suppressive doses. Long-term survival rate for well differentiated thyroid cancer is over $90 \%{ }^{4}$. However, in $30 \%$ of patients tumor recurrence is observed, with $70 \%$ of these recurrences occurring within the first decade after therapy and the rest years later ${ }^{5}$. Thus, life-long follow-up is required to assess the prognosis of the tumor. 
Thyroglobulin $(\mathrm{Tg})$ is produced exclusively by thyroid follicular cells and represents a sensitive marker for detection of local recurrence or thyroid cancer metastases after ablation ${ }^{6}$. It is noteworthy that the presence of anti-thyroglobulin antibodies, which have been reported in up to $25 \%$ of patients with thyroid cancer, may invalidate the significance of serum $\mathrm{Tg}$ measurement ${ }^{7}$. The performance of radioiodine scans requires the withdrawal of thyroid hormone therapy in order to achieve high TSH secretion ${ }^{8}$. However, the withdrawal of thyroid hormone results in severe hypothyroidism with such symptoms as extreme fatigue, depression, freezing sensation, and consequently, a markedly reduced quality of life (QOL) ${ }^{9}$. Recently, the introduction of recombinant human thyrotropin (rhTSH/ Thyrogen, Genzyme Corp., MA, USA) has significantly changed the procedure of follow-up evaluation of patients post thyroidectomy and radioiodine ablation ${ }^{10,11}$. rhTSH is produced from human subunit genes transfected into Chinese hamster ovary cell lines ${ }^{12}$. The administration of rhTSH for diagnostic whole-body scans and $\mathrm{Tg}$ measurement has proved comparable to thyroid hormone withdrawal in the detection of residual or recurrent thyroid cancer ${ }^{13}$. The use of rhTSH appears to be safe and reliably provides high concentrations of TSH while preserving the QOL of the patients by avoiding debilitating hypothyroidism $^{11}$.

We here report our experience with rhTSH in a small group of patients with well-differentiated thyroid cancer who were evaluated for residual or metastatic disease. The objective was to determine the diagnostic potency and safety of rhTSH. We further report the use of rhTSH as a therapeutic adjunct in two patients with metastatic disease.

\section{MATERIALS AND METHODS}

\section{Patients}

Seven patients ( 2 males, 5 females), mean age: $48 \mathrm{yr}$ (range: $38-57 \mathrm{yr}$ ), were included in the study. Inclusion criteria were a detectable serum $\mathrm{Tg}(>1 \mathrm{ng} / \mathrm{ml})$ on thyroxine suppressive therapy and negative antiTg antibodies. All 7 patients had undergone a surgical thyroidectomy and radioiodine-131 ablation at least 12 months prior to the evaluation. Five of the patients had a papillary, one had follicular and one papillaryfollicular thyroid carcinoma. Exclusion criteria were the presence of anti-Tg antibodies, pregnancy or radioiodine treatment within the previous months.

\section{Protocol}

All patients received $0.9 \mathrm{mg}$ rhTSH by intramuscular injection on days 1 and 2 . Five $\mathrm{mCi}$ of ${ }^{131} \mathrm{I}$ were administered orally on day 3 and a WBS was performed on day 5. Determination of serum Tg and TSH were performed on day 1, prior to the first rhTSH injection, and on days 3 (n: 3 ) and 5.

Two out of the seven patients, who presented metastases at the liver, the sternum, the lung and the right frontal skull, were subsequently treated with radioiodine ${ }^{131}$ I after the administration of rhTSH for 2 consecutive days at the dose of $0.9 \mathrm{mg}$ per day.

\section{Measurements}

Serum Tg levels were determined by IRMA (BykSangtec, Dietzenbach, Germany) with a detection limit $<0.075 \mathrm{ng} / \mathrm{ml}$. The inter-assay coefficient of variation (CV) at $0.6 \mathrm{ng} / \mathrm{ml}$ was $9.1 \%$ and at $4 \mathrm{ng} / \mathrm{ml}$ was $2.9 \%$, whereas the intra-assay $\mathrm{CV}$ at $0.39 \mathrm{ng} / \mathrm{ml}$ and at $4 \mathrm{ng} /$ $\mathrm{ml}$ was $10.5 \%$ and $2.2 \%$, respectively. The normal range for Tg was $2-70 \mathrm{ng} / \mathrm{ml}$. The functional sensitivity of the assay was calculated at $0.8 \mathrm{ng} / \mathrm{ml}$ and we arbitrary selected $1 \mathrm{ng} / \mathrm{ml}$ as the cut-off level discriminating undetectable from detectable $\mathrm{Tg}$ levels.

TSH was measured by chemiluminescence with a TSH- $3^{\text {rd }}$ generation assay (Nichols, San Juan Capistrano, CA, USA). The normal values ranged from 0.3 to $4 \mathrm{mU} / \mathrm{L}$. The mean intra-assay $\mathrm{CV}$ at $0.01 \mathrm{mU} / \mathrm{L}$ was $12 \%$ and at $1.29 \mathrm{mU} / \mathrm{L}$ was $4.6 \%$. The inter-assay $\mathrm{CV}$ at $0.02 \mathrm{mU} / \mathrm{L}$ and at $1.28 \mathrm{mU} / \mathrm{L}$ was $15 \%$ and $5.5 \%$, respectively.

\section{RESULTS}

Serum TSH levels peaked on day 3 at $127 \pm 44$ $\mathrm{mU} / \mathrm{L}($ mean $\pm \mathrm{SD})$ and decreased to $14 \pm 3.3 \mathrm{mU} / \mathrm{L}$ on day 5 (Figure 1).

All seven patients had a basal serum $\mathrm{Tg}$ (b-Tg) concentration above $1 \mathrm{ng} / \mathrm{ml}$ (Table 1 ). The response of $\mathrm{Tg}$ to Thyrogen was analogous to the basal level. Three patients with a b- Tg at $1.7 \mathrm{ng} / \mathrm{ml}, 2.2 \mathrm{ng} / \mathrm{ml}$ and $3.1 \mathrm{ng} / \mathrm{ml}$, respectively, presented a rise after Thyrogen $(\mathrm{s}-\mathrm{Tg}$ ) of $3.3 \mathrm{ng} / \mathrm{ml}, 5 \mathrm{ng} / \mathrm{ml}$ and $7 \mathrm{ng} / \mathrm{ml}$, respectively. In these patients the clinical evaluation and imaging studies like ultrasound (US), magnetic reso- 


\section{TSH}

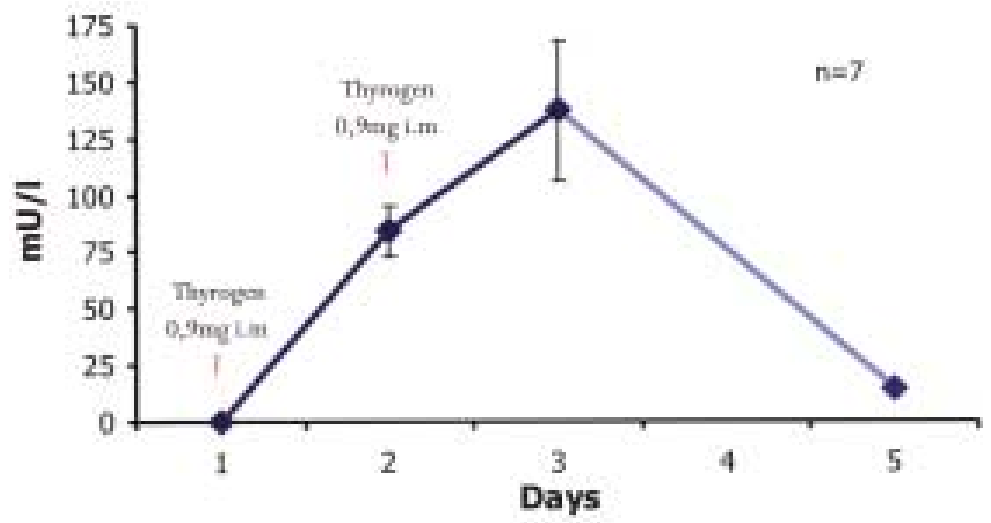

Figure 1. Basal and rhTSH stimulated serum TSH (mean \pm SD) values in 7 patients with differentiated thyroid cancer.

nance (MRI) and WBS failed to detect metastatic lesion and only follow-up was recommended.

One out of the seven patients had a b-Tg value of $5 \mathrm{ng} / \mathrm{ml}$ and s-Tg of $17 \mathrm{ng} / \mathrm{ml}$, whereas another had a b-Tg at $11 \mathrm{ng} / \mathrm{ml}$ and sTg at $84 \mathrm{ng} / \mathrm{ml}$ (Table 1). Both these patients had a negative WBS; they showed a comparable increase of serum $\mathrm{Tg}$ after withdrawal of thyroid hormone (hypo-Tg $19 \mathrm{ng} / \mathrm{ml}$ and $91 \mathrm{ng} / \mathrm{ml}$, respectively). These two patients were treated with $100 \mathrm{mCi}(3700 \mathrm{MBq}){ }^{131} \mathrm{I}$. Post-therapy scan was negative and a re-evaluation is planned in six months.

One patient, a 38-year old female, presented a b$\mathrm{Tg}$ at $4.4 \mathrm{ng} / \mathrm{ml}$, and a s- $\mathrm{Tg}$ of $78 \mathrm{ng} / \mathrm{ml}$ on day 3. The patient was thyreoidectomised and radioiodine ablated in 1980 because of a mixed papillary-follicular carcinoma. She remained free of any recurrent disease for about 20 years. In the summer of 2002, b-Tg was found to be increased and metastases were detected

Table 1. Tg values prior to and after administration of Thyrogen

\begin{tabular}{cccc}
\hline No. Patients & $\begin{array}{c}\text { Basal-Tg } \\
\text { Day 1 (ng/ml) }\end{array}$ & $\begin{array}{c}\text { Stimulated-Tg } \\
\text { Day 3 (ng/ml) }\end{array}$ & $\begin{array}{c}\text { Stimulated-Tg } \\
\text { Day 5 (ng/ml) }\end{array}$ \\
\hline 1 & 1.7 & - & 3.3 \\
2 & 2.2 & 6.3 & 5 \\
3 & 3.1 & - & 7 \\
4 & 5 & 15 & 17 \\
5 & 11 & - & 84 \\
6 & 4.4 & 78 & 81 \\
7 & 16 & - & 77
\end{tabular}

$-:$ not determined by L-thyroxine withdrawal, subsequent to which she was treated with $150 \mathrm{mCi}(5500 \mathrm{MBq}){ }^{131} \mathrm{I}$. Thyrogen administration revealed a metastatic uptake at the posterior site of the liver, on the sternum and on the frontal skull (Figure 2). The patient was again treated with $150 \mathrm{mCi}^{131} \mathrm{I}$ after preparation with rhTSH; Thyrogen was administered $0.9 \mathrm{mg}$ intramuscularly each day, for the two days prior to the ${ }^{131} \mathrm{I}$ administration.

Another patient, a 54-year-old female had a b-Tg of $16 \mathrm{ng} / \mathrm{ml}$ and an ${ }^{131} \mathrm{I}$ metastatic uptake in the WBS after Thyrogen, at the apical lung field. She was also treated with $150 \mathrm{mCi}^{131} \mathrm{I}$ after preparation with Thyrogen. Six months after radioiodine treatment, $\mathrm{b}-\mathrm{Tg}$ and $\mathrm{s}-\mathrm{Tg}$ were $<1 \mathrm{ng} / \mathrm{ml}$ and she had a negative WBS.

It should be noted that no patient had a visible radioiodine uptake in the thyroid bed, thus indicating

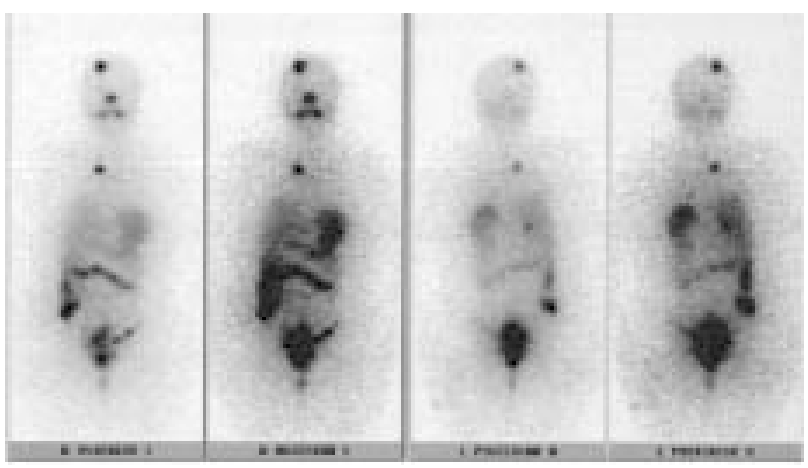

Figure 2. Anterior and posterior view of metastases on the frontal skull, the sternum and the liver, revealed by WBS, following rhTSH administration. 
successful ablation. No side effects or complains were reported after Thyrogen administration.

\section{DISCUSSION}

The administration of rhTSH resulted in a variable increase of $\mathrm{Tg}$ in all 7 patients and revealed metastatic disease by WBS in two out of the seven patients.

Three patients had a slight increase of serum $\mathrm{Tg}$ levels and a negative WBS. They were not treated as Tg levels above $10 \mathrm{ng} / \mathrm{ml}$ are considered as a cut-off value for treatment of residual or recurrent thyroid cancer ${ }^{14}$. Two patients had rhTSH stimulated Tg levels $(>10 \mathrm{ng} / \mathrm{ml})$ with a negative WBS. No tumor was detected on radiological and US evaluation or by means of the traditional hypothyroid preparation WBS. They were consequently treated with doses of ${ }^{131} \mathrm{I}$, as normally used for ablation ${ }^{15}$. These data may indicate that rhTSH is useful in the management of patients with positive s-Tg and negative WBS (and negative US examination), specifically in distinguishing between patients who simply need a follow-up from those requiring therapeutic procedures. In the evaluation of these patients, rhTSH proved to be comparable to that after withdrawal of thyroid hormone, in accordance with recent reports ${ }^{16,13}$.

In patients with increased serum $\mathrm{Tg}$ levels and negative ${ }^{131}$ I scans, a ${ }^{18}$ Fluoro-2-deoxy-D-glucose - positron emission tomography (FDG-PET) examination, may permit selection of patients for curative surgery ${ }^{17}$. Recently, it was demonstrated that TSH stimulates FDG uptake by differentiated thyroid cancer (DTC) and, therefore, FDG-PET may be more accurate under rhTSH than under suppression therapy ${ }^{18}$.

In parallel with the development of a simple Tgstimulation test not requiring thyroid hormone withdrawal, such as the rhTSH test, the technical evolution of new assays for $\mathrm{Tg}$ with improved precision $(<1$ $\mathrm{ng} / \mathrm{ml}$ ) has certainly facilitated the diagnostic and therapeutic management of patients with DTC ${ }^{19}$.

In two of our seven patients, metastatic disease requiring further treatment was detected after thyroid hormone withdrawal as well as on rhTSH scan. These two patients were treated with ${ }^{131} \mathrm{I}$ after preparation with Thyrogen. Both patients had suffered considerably in previous evaluations from the withdrawal of thyroid hormone and therefore Thyrogen administration before treatment was considered as "compassionate use" ${ }^{20,21}$. One of these two patients responded splendidly, being free of disease six months later. The other will be evaluated in a few months time.

There is no established protocol for using rhTSH to prepare the patient for ${ }^{131} \mathrm{I}$. These two patients are among the few who have been diagnosed by rhTSH and in whom rhTSH was subsequently administered to stimulate TSH secretion prior to radioiodine treatment. As both of our patients who received rhTSH prior to ${ }^{131} \mathrm{I}$ therapy reported no side effects and the radioiodine by the metastatic lesions uptake was stimulated by rhTSH, we suggest that this treatment modality possibly constitutes a valid alternative to the classic therapeutic schedule requiring the interruption of $L$ thyroxine. In a retrospective analysis of the use of rhTSH as preparation for radioiodine thyroid remnant ablation, it was reported that $84 \%$ of the patients prepared by rhTSH and $81 \%$ of those prepared by hormone withdrawal had complete resolution of visible thyroid bed uptake after ablation ${ }^{22}$. There are no prospective studies on the use of rhTSH as a treatment agent in patients with metastases due to thyroid cancer. In a case report, rhTSH was applied in a patient with thyroid cancer, primary empty sella and isolated deficiency of thyrotropin, in order to adequately stimulate the malignant tissue and optimize radioiodine uptake by the tumor cells ${ }^{23}$.

The small number of patients in our report does not allow firm conclusions regarding future rhTSH assisted treatment. It is obvious that prospective and randomized studies are urgently needed. It is also noteworthy that serum peak TSH levels after rhTSH administration might be influenced by body size, and this may indicate that in future studies doses rhTSH should be adjusted to body size ${ }^{24}$.

The detection of skull metastases by rhTSH in one of our patients may be added to other studies reporting the use of rhTSH for the diagnosis of metastases due to DTC. Thus, sella metastasis and hypopituitarism due to thyroid cancer were revealed by rhTSH $^{25}$. A highly functional metastatic struma ovarii from follicular thyroid carcinoma has recently been diagnosed and subsequently treated by rhTSH combined with lesional and whole body dosimetry ${ }^{26}$. The wide use of rhTSH for diagnostic and potential therapeutic purposes in the future may significantly ameliorate the 
QOL of thyroid cancer patients ${ }^{27}$. In this context, rhTSH may be established as a safe and reliable agent improving the QOL of patients undergoing Tg testing and radioiodine scanning ${ }^{9}$.

The cost of rhTSH is not negligible. However, in the long term this cost may prove less than the indirect economic consequences on society of repeated episodes of hypothyroidism. In a study from the Netherlands, costs incurred through loss of productivity owing to hypothyroidism were estimated to be quite $\operatorname{high}^{28}$. Thus, in order to reduce such negative repercussions on society, a comprehensive review of both the direct and indirect consequences of a therapeutic approach of this type is necessary to ascertain the most appropriate measures to be taken.

In conclusion, our results indicate that rhTSH is a reliable agent for the diagnosis of metastatic thyroid cancer disease, which increases the sensitivity of serum $\mathrm{Tg}$ testing, enhances iodine uptake and improves the QOL of patients with DTC. Moreover, it may represent a valuable agent for the preparation of patients for radioiodine treatment.

\section{REFERENCES}

1. Woolam GL, 2000 Cancer Statistics 2000: a benchmark for the new century. CA Cancer J Clin 50: 6.

2. Ain KB, 1995 Papillary thyroid carcinoma. Etiology, assessment, and therapy. Endocrinol Metab Clin North Am 24: 711-760.

3. Ron E, Lubin J, Schneider AB, 1992 Thyroid cancer incidence. Nature 360: 113.

4. Mazzaferri EL, 1999 An overview of the management of papillary and follicular thyroid carcinoma. Thyroid 9: 421427.

5. Mazzaferri EL, Jhiang SM, 1994 Long-term impact of initial surgical and medical therapy on papillary and follicular thyroid cancer. Am J Med 97: 418-428.

6. Torrens J, Burch HB, 2001 Serum thyroglobulin measurement: utility in clinical practice. Endocrinol Metab Clin North Am 30: 1-34.

7. Van Herle AJ, Uller RP, Mathwes NI, Brown J, 1973 Radioimmunoassay for measurement of thyroglobulin in human serum. J Clin Invest 52: 1320-1327.

8. Cavalieri RR, 1996 Nuclear Imaging in the management of thyroid carcinoma. Thyroid 6: 485-492.

9. Dow KH, Ferrell BR, Anello C, 1997 Quality-of-life changes in patients with thyroid cancer after withdrawal of thyroid hormone therapy. Thyroid 7: 613-619.

10. Mazzaferri EL, Kloos RT, 2000 Using recombinant human TSH in the management of well-differentiated thyroid cancer. Current strategies and future directions.
Thyroid 10: 767-778.

11. Meier CA, Braverman LE, Ebner SA, et al, 1994 Diagnostic use of recombinant human thyrotropin in patients with thyroid carcinona (phase I/II study). J Clin Endocrinol Metab 78: 188-196.

12. Szkudlinski MW, Thotakura NR, Bucci I, et al, 1993 Purification and characterization of recombinant human thyrotropin (TSH) isoforms produced by Chinese hamster ovary cells: the role of sialylation and sulfation in TSH bioactivity. J Clin Endocrinol Metab 133: 1490-1503.

13. Haugen BR, Pacini F, Reiners C, et al, 1999 A comparison of recombinant human thyrotropin and thyroid hormone withdrawal for the detection of thyroid remnant or cancer. J Clin Endocrinol Metab 84: 3877-3885.

14. Pacini F, Molinaro E, Lippi F, et al, 2001 Prediction of disease status by recombinant human TSH-stimulated derum $\mathrm{Tg}$ in the postsurgical follow-up of differentiated thyriod carcinoma. J Clin Endocrinol Metab 86: 56865690.

15. Fatourechi V, Hay ID, 2000 Treating the patient with differentiated thyroid cancer with thyroglobulin-positive iodine-131 diagnostic scan negative metastases: including comments on the role of serum thyroglobulin monitoring in tumor surveillance. Semin Nucl Med 30: 107-114.

16. Robbins RJ, Tuttle M, Sharaf RN, et al, 2001 Preparation by recombinant human thyrotropin or thyroid hormone withdrawal are comparable for the detection of residual differentiated thyroid carcinoma. J Clin Endocrinol Metab 86: 619-625.

17. Schlóter B, Bohuslavizki KH, Beyer W, Plotkin M, Buchert R, Clausen M, 2001 Impact of FDG PET on patients with differentiated thyroid cancer who present with elevated thyroglobulin and negative ${ }^{131}$ I scan. J Nucl Med 42: 71-78.

18. Petrich T, Boerner AR, Otto D, Hofmann M, Knapp WH, 2002 Influence of rhTSH on $\left[{ }^{18} \mathrm{~F}\right]$ fluorodeoxyglucose uptake by differentiated thyroid carcinoma. Eur J Nucl Med 29: 641-647.

19. Morgenthaler NG, Froehlich J, Rendl J, et al, 2002 Technical Evaluation of a new immunoradiometric and a new immunoluminometric assay for thyroglobulin. Clin Chem 48: 1077-1083.

20. Berg G, Lindstedt G, Suurkóla M, Jansson S, 2002 Radioiodine ablation and therapy in differentiated thyroid cancer under stimulation with recombinant human thyroid-stimulating hormone. J Endocrinol Invest 25: 44-52.

21. Rudavsky AZ, Freeman LM, 1997 Treatment of scan-negative, thyroglobulin-positive metastatic thyroid cancer using radioiodine ${ }^{131} \mathrm{I}$ and recombinant human thyroid stimulating hormone. J Clin Endocrinol Metab 82: 11-14.

22. Robbins RJ, Larson SM, Sinha N, et al, 2002 A retrospective review of the effectiveness of recombinant human TSH as a preparation for radioiodine thyroid remnant ablation. J Nucl Med 43: $1482-1488$.

23. Risse JH, Grünwald F, Bender H, Schüller H, van Roost D, Biersack HJ, 1999 Recombinant human thyrotropin in thyroid cancer and hypopituitarism due to sella metastasis. Thyroid 9: 1253-1256. 
24. Vitale G, Lupoli GA, Ciccarelli A, et al, 2003 Influence of body surface area on serum peak thyrotropin (TSH) levels after recombinant human TSH administration. J Clin Endocrinol Metab 88: 1319-1322.

25. Colleran KM, Burge MR, 1999 Isolated thyrotropin deficiency secondary to primary empty sella in a patient with differentiated thyroid carcinoma: an indication for recombinant thyrotropin. Thyroid 9: 1249-1252.

26. Rotman-Pikielny P, Reynolds JC, Barker WC, Yen PM, Skarulis MC, Sarlis NJ, 2000 Recombinant human thy- rotropin for the diagnosis and treatment of a highly functional metastatic struma ovarii. J Clin Endocrinol Metab 85: 237-244.

27. Ferrell B, Dow KH, 1997 Quality of life among long term cancer survivors. Oncology 11: 565-571.

28. Nijhuis TF, Van Weperen W, De Klerk JMH, 1999 Costs associated with the withdrawal of thyroid hormone suppression therapy during the follow-up treatment of welldifferentiated thyroid cancer. Tijdschr Nucl Geneeskd 21: 98-100. 